\title{
REGIONALIZAÇÃO DA OCORRÊNCIA DOS DESASTRES NATURAIS NO RIO GRANDE DO SUL NO PERÍODO 2003 - 2009. PARTE I: INUNDAÇÃO BRUSCA
}

Anderson Spohr Nedel ${ }^{1}$; Tania Maria Sausen; Silvia Midori Saito

${ }^{1}$ Faculdade de Meteorologia, Universidade Federal de Pelotas; anderson.nedel@ ufpel.edu.br

\section{RESUMO}

Esse estudo tem por objetivo realizar um zoneamento dos desastres naturais, secas e inundações bruscas ocorridos no estado do Rio Grande do Sul (RS), entre os anos 2003 e 2009, baseado nos decretos de ocorrência destes eventos pela defesa civil do Estado. Foram utilizadas todas as notificações de inundações bruscas, obtidas junto a Coordenadoria Estadual de Defesa Civil do RS (CEDEC). Os resultados mostraram que em relação à inundação brusca (enxurrada), as regiões mais afetadas foram a Depressão Central gaúcha (35\%), as partes baixas do Planalto Médio (18\%), Alto Uruguai (14\%), Encosta inferior do Nordeste (10\%) e as Missões (9\%). O final da primavera e o início do verão (dezembro) foram as épocas mais frequentes para suas ocorrências. Foi mostrado, também, que estes eventos adversos não acontecem somente em anos com a presença dos fenômenos climáticos El Niño e La Niña. Houve ocorrências de severos episódios no RS em anos classificados como neutros - sem a presença destes fenômenos climáticos.

\section{ABSTRACT}

This paper aims to carry out a mapping of natural disasters, gradual floods, occurring in Rio Grande do Sul (RS) state from period 2003 a 2009. Records of the events were obtained by State Civil Defense Authority to analyze the preferential period for these occurrences and the most affected areas. The results show that regarding the gradual floods, the most affected areas of RS were Depressão central (35\%), the lowlands of Planalto Médio (18\%), Alto Uruguai (14\%), Encosta inferior do Nordeste (10\%) and Missões (9\%) regions. The period between the spring (finish) and summer (begin) season was preferential for occurrences. Also was found that gradual floods did not occur only in years with presence of El Niño and 
La Niña climatic events. It's also occurred in periods without the influence of these phenomena (neutral years).

\section{INTRODUÇÃO}

Há evidências que ao longo dos últimos anos as precipitações e os eventos extremos de tempo têm aumentado em intensidade e frequência. De acordo com alguns pesquisadores, esse fato pode estar diretamente relacionado às ações do homem. A urbanização acelerada das cidades, a impermeabilização do solo, o desmatamento e o assoreamento dos rios, o mau planejamento e utilização das bacias hidrográficas, o aumento da poluição atmosférica, etc., são alguns exemplos. Segundo o Painel Intergovernamental sobre Mudanças Climáticas (Marengo et al, 2009) “(...) em muitas regiões da América do Sul, a frequência de eventos de precipitação tem aumentado, consistentemente com o aquecimento, e em várias regiões alterações nos extremos de temperatura têm sido observadas nos últimos 50 anos".

O objetivo deste trabalho é realizar um zoneamento dos desastres naturais por inundações bruscas, ocorridos no estado do Rio Grande do Sul (RS) entre os anos 2003 e 2009, baseado nas notificações (ocorrências) da defesa civil do Estado.

\section{MATERIAIS E MÉTODOS}

Para a realização deste estudo foram utilizadas informações sobre inundações bruscas (enxurradas) ocorridas no período entre os anos 2003 e 2009 no RS. Os dados foram obtidos junto à Secretaria Estadual de Defesa Civil do estado, a qual é frequentemente notificada pelos próprios municípios atingidos sobre a ocorrência de algum evento adverso (cuja intensidade pode fazer o município decretar Situação de Emergência - SE). Os dados foram organizados e selecionados de acordo com os tipos de eventos e datas de ocorrências, a fim de analisar as frequências mensais e os períodos em que estes ocorreram. Também foram verificadas (para cada evento) as regiões mais afetadas e os municípios mais atingidos durante o período estudado. Para a delimitação do zoneamento foram utilizadas as regiões fisiográficas do RS, as quais foram definidas de acordo com as suas características geoambientais. 


\section{RESULTADOS E DISCUSSÕES}

A Figura $1(a, b)$ apresenta as notificações de ocorrências dos eventos que atingiram o RS entre 2003 e 2009. Pode-se notar, através da figura, que esses eventos aconteceram predominantemente durante a primavera. O mês de dezembro (início) foi o que apresentou maior número de ocorrências de inundações bruscas (54 eventos), seguido pelos meses de setembro (19 eventos) e outubro (18 eventos), respectivamente (figura 6b). O período de início e término de cada estação do ano baseou-se nas seguintes datas: outono, 20/03 a 19/06; inverno, 20/06 a 21/09; primavera, 22/09 a 20/12 e verão, 21/12 a 19/03.

(a)

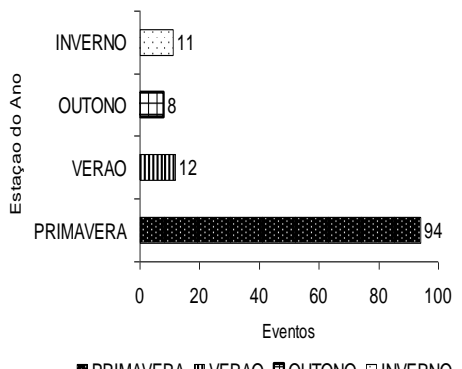

Figura 1: Frequência de ocorrência das inundações bruscas no RS

A distribuição espacial dos eventos de inundação brusca pode ser vista na Figura 2. As inundações bruscas afetaram várias partes do Estado. Quase a metade destes episódios (50\%) estabeleceu-se em municípios das regiões Depressão Central, Encosta Inferior do Nordeste e Encosta do Sudeste, as quais são caracterizadas por relevos ligeiramente ondulados e inclinados com altitudes que, normalmente, não ultrapassam os 100 metros. Outras regiões frequentemente atingidas pelas enxurradas foram as partes planas do Planalto Médio (18\%) e Alto Uruguai (14\%). 


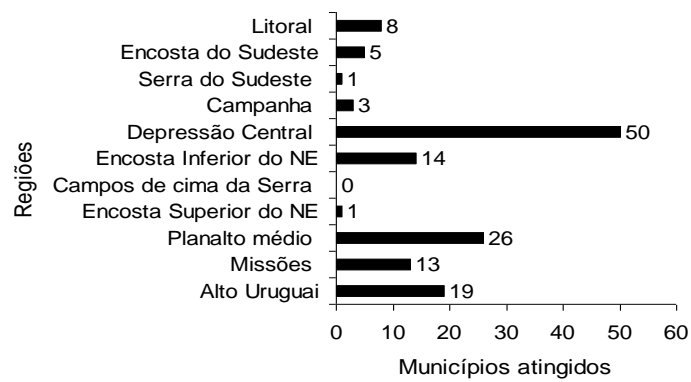

Figura 2: Distribuição espacial das inundações bruscas ocorridas no estado do Rio Grande do Sul, no período 2003 a 2009.

\section{CONCLUSÕES}

A distribuição espacial das inundações mostrou que aproximadamente a metade dos episódios estabeleceu-se em municípios do RS pertencentes às regiões Depressão Central e das Encostas inferior do nordeste e do sudeste. Outras regiões frequentemente atingidas por enxurradas foram as partes planas do Planalto Médio (18\%) e Alto Uruguai (14\%). A maioria destes ocorre na primavera e no início do mês de dezembro. O comportamento anual das inundações mostra uma maior frequência nos anos 2003, 2007 e 2009 (principalmente), ano de El niño (2009-10) (não apresentados aqui).

\section{BIBLIOGRAFIA}

FORTES, A. B., 1959: Geografia Física do Rio Grande do Sul. Ed. Globo. Porto Alegre/RS, Brasil.

MARENGO, J. A.; JONES R.; ALVES, L; VALVERDE, M., 2009: Future change of temperature and precipitation extremes in South America as derived from the PRECIS regional climate modeling system. International Journal of Climatology (In press).

SECRETARIA ESTADUAL DE DEFESA CIVIL RS. Centro de Operações da Defesa Civil. Disponível em www.defesacivil.rs.gov.br. Acesso em 16/01/2010. 